\title{
National Program of Opisthorchiasis in Thailand; Situation and Policy Strategy
}

\author{
Kitphati, R., ${ }^{1}$ Watanawong, O., ${ }^{2}$ Wongsaroj, T. ${ }^{2}$ and Nithikathkul, C. ${ }^{3 *}$ \\ ${ }^{1}$ Office of Permanent Secretary, Ministry of Public Health, Nonthaburi, Thailand \\ E-mail: drrungeng@hotmail.com \\ ${ }^{2}$ Bureau of General Communicable Diseases, Department of Disease Control, Ministry of Public Health, \\ Nonthaburi, Thailand, E-mail: thitima4244@gmail.com \\ ${ }^{3}$ Tropical and Parasitic Diseases Research Unit, Faculty of Medicine, Mahasarakham University, \\ Mahasarakham, Thailand, E-mail: nithikethkul2016@gmail.com \\ *Correspondence Author
}

\begin{abstract}
Opisthorchiasisis, a chronic parasitic inflammatory disease of the bile ducts, caused by liver fluke or Opisthorchis viverrini infections is a crucial significant public health problem in Thailand. Most evidence of Opisthorchiasis is reported from national programs. Thus the magnitude of liver fluke infection at the national level required to assess the effectiveness of the national opisthorchiasis control program. In Thailand, infections with Opisthorchis viverrini are associated with a high mortality secondary to Cholangiocarcinoma (CCA). A systematic countrywide national survey in Thailand already reported from the past more than half-century (59 years) in 1957 to date in 2019, revealed the declining trend of the overall helminthiasis infection from $62.9 \%$ (in 1957) to $8.13 \%$ (in 2009). The National Opisthorchiasis control program managers have initiated and established a national plan to prevent and control these eradicate diseases through the interaction and responses of the provincial public health sectors. However, the national control program managers need to have information determined by evidence-based needs. These intensive data are representative of all ages of the population of Thailand and are derived from the national household survey. The national prevalence of Opisthorchis viverrini in this study was carried out in 77 provinces. A total of 9,904 samples of stool specimens were obtained from the population by using a cluster random sampling under WHO guidelines. The results of this large scale survey showed that the overall prevalence of Opisthorchaisis among Thai people was 4.0\%. The highest prevalence of $O$. viverrini was $11.9 \%$, in the health region 5 in the Northeast region. During this national survey of Opisthorchiasis, geographic information is also conducted to investigate the prevalence of $O$. viverrini. The spatial analysis would be the trends and analyze the risk factors that correlate with infections among rural Thai people. The recommendation that already showed the impact of National program useful for every country especially in Mae King basin for elimination and control for opisthorchiasis.
\end{abstract}

\section{Introduction}

The liver fluke infection is caused by Opisthorchis viverrini, and Clonorchis sinensis still an important public health problem in many parts of southeast Asia, China, Republic south Korea especially in Mekong basin, which including Thailand. (Lun et al., 2005, Rim, 2005, Jeong et al., 2016, Qian et al., 2016, Sripa et al., 2007 and 2011) The main infection by the fish-borne trematode and cause of intrahepatic bile duct diseases such as cholangitis, hepatomegaly and cholangiocarcinoma. (Sithithaworn et al., 1997 and Yoshida et al., 2019) In 1994, Opisthorchis viverrini was classified to be a carcinogen (Group 1) (Bouvard et al., 2009 and Baisson, 2017) Along with global warming, rapidly increasing of science, technology, higher innovation is becoming increasingly available, accompanied by integration in public health. Thailand, endemic parasitic diseases infections are mainly related to the socio-economic, development process and risk behaviours. (Sithithaworn and Haswell-Elkins, 2003, Sripa et al., 2007, Bouvard et al., 2009, Wattanayingcharoenchai et al., 2011, Sripa et al., 2011, Yong et al., 2014 and Sripa and Echaubard, 2017) In Thailand, Opisthorchiasis is also the highest public health problem which had been recognized as the main parasitic zoonoses which stated as the national control programs in Thailand. The strategy of prevention and control programs dealing with parasitic progress, many crucial factors influence the transmission rates of infection. In the case of opisthorchiasis, the raw consumption habit or undercooked fish is the primary source of 
ransmission for infection (Jongsuksuntigul and Imsomboon, 1997 and 2003 and Sripa and Echaubard, 2017). Environmental management, unsanitary latrines and the prevalence of reservoirs, intermediate host as a freshwater fish, are main factors that contribute to high rates of infection especially in Northeast and North Thailand (Jongsuksuntigul and Imsomboon, 1997 and 2003, Radomyos et al., 1998). In the endemic area of transmission, several kinds of food preparations contain uncooked fish such as fermented fish. The main local famous food for villager was Koi Pla (contain raw fish flesh chopped with garlic, lemon juice, fish sauce, chilly, roasted ground rice and vegetables) is probably the main route of infection, followed by fermented fish by preserved less than seven days, such as Pla Som, Pla Ra and Jaewbhong (Sithithaworn and Haswell-Elkins, 2003 and Suwannahitatorn et al., 2019). Based on a regional survey the overall prevalence of opisthorchiasis in north-eastern Thailand was as high as $34.6 \%$ (Jongsuksuntigul and Imsomboon, 1997). As a consequence, the Ministry of Public Health started in 1984 a liver fluke control program, which was expanded in 1988 to cover all 19 north-eastern provinces. During 2009. The Department of Disease Control collaborates with networks from Medical schools and Universities establish National Strategy program for prevention and Control 2009-2022. The main strategies for this control are comprised of 3 interrelated approaches, namely stool examinations and treatment of positive cases with praziquantel for eliminating human host reservoir; health education for a promotion of cooked fish consumption to prevent infection; and the improvement of hygienic defecation for the interruption of disease transmission. The national survey of the Neglected Tropical Diseases in Thailand and risk behaviours can then be used in targeted surveillance and prevention program for Opisthorchiasis control in the identified high-risk groups. This study was thought to provide useful national survey data about the health status that might be addressed by targeted treatment or education as a strategy for parasite control in the future.

\section{Methodology}

This national program with the cross-sectional survey was investigated in 77 provinces during the period of the Year 2014. Investigators visited randomly selected areas of the districts, accompanied by local Public Health officials. After taking informed consent, 9,904 individuals from all age groups were interviewed and stool samples were collected. Stool specimens were fixed with formalin and stored before examination in the laboratory of national survey programmers. Modified Kato Katz technique was performed to quantify the intensity of parasites from $20 \%$ of the positive samples of Opisthorchis vivirrini (Ritchie, 1948, Katz et al., 1972 and WHO, 1980) The presence of helminths parasite eggs was determined microscopically. The positive cases were treated with either albendazole and praziquantel (Dietrich and Wegner, 1984, WHO, 1990, Wattanayingcharoenchai et al., 2011, Nithikathkul et al., 2017 and Wongsaroj et al., 2014). Data were analyzed by using descriptive statistics of percentages, mathematical means and standard deviation to determine the prevalence rates and intensity.

Ministry of Public health divided 12 Health regions or Area Health, which is a mechanism of the ministry of Public health at the provincial level. One zone will have a population of 3-6 million people. It is the main mechanism for the development of the health service system. Health promotion and disease prevention system, Consumer protection system, the main management with service plans (www.hsri.or.th). The National recommendation data of Opisthorchiasis prevention control program is developing the surveillance of health geographic information model for Opisthorchiasis prevention in Thailand. Data were analyzed using descriptive statistics of percentages to determine the prevalence rates. A GIS database for the study of Opisthorchiasis was implemented using an ArcGIS Desktop program from the ESRI company (Wongsaroj et al., 2012 and 2014).

\section{Results}

Overall 9,904 subjects were recruited including all age-groups from 1 year of age to more than 60 years. Of these, 4,008 were males and 5,896 were females (male to female ratio 1:1.47) (Table 1). The highest prevalence (11.1 per cent) were found in villagers aged 56-60 years and 61-65 years. (Table 2 ). The overall prevalence of Opisthorchiasis in Thailand approximately $4.00 \%$. The majority of prevalence still high more than $10 \%$ in Northeastern and Northern part of Thailand. In the central and southern part of Thailand, the prevalence still lower than $5 \%$ (Figure 1)

\subsection{The National Program between 2009 and 2014}

The geographic information system of Opisthorchiasis in the Year 2009 Showed the highest prevalence in Health Region 7, 10, 6, 5 and 8 were $20.21 \%, 15.83 \%, 14.7,12.77 \%$ and $12.70 \%$ respectively. The overall prevalence was $8.13 \%$ in Figure 2. The map showed, in region 7 the prevalence was slightly high level. They were two water sources in region 7 . 


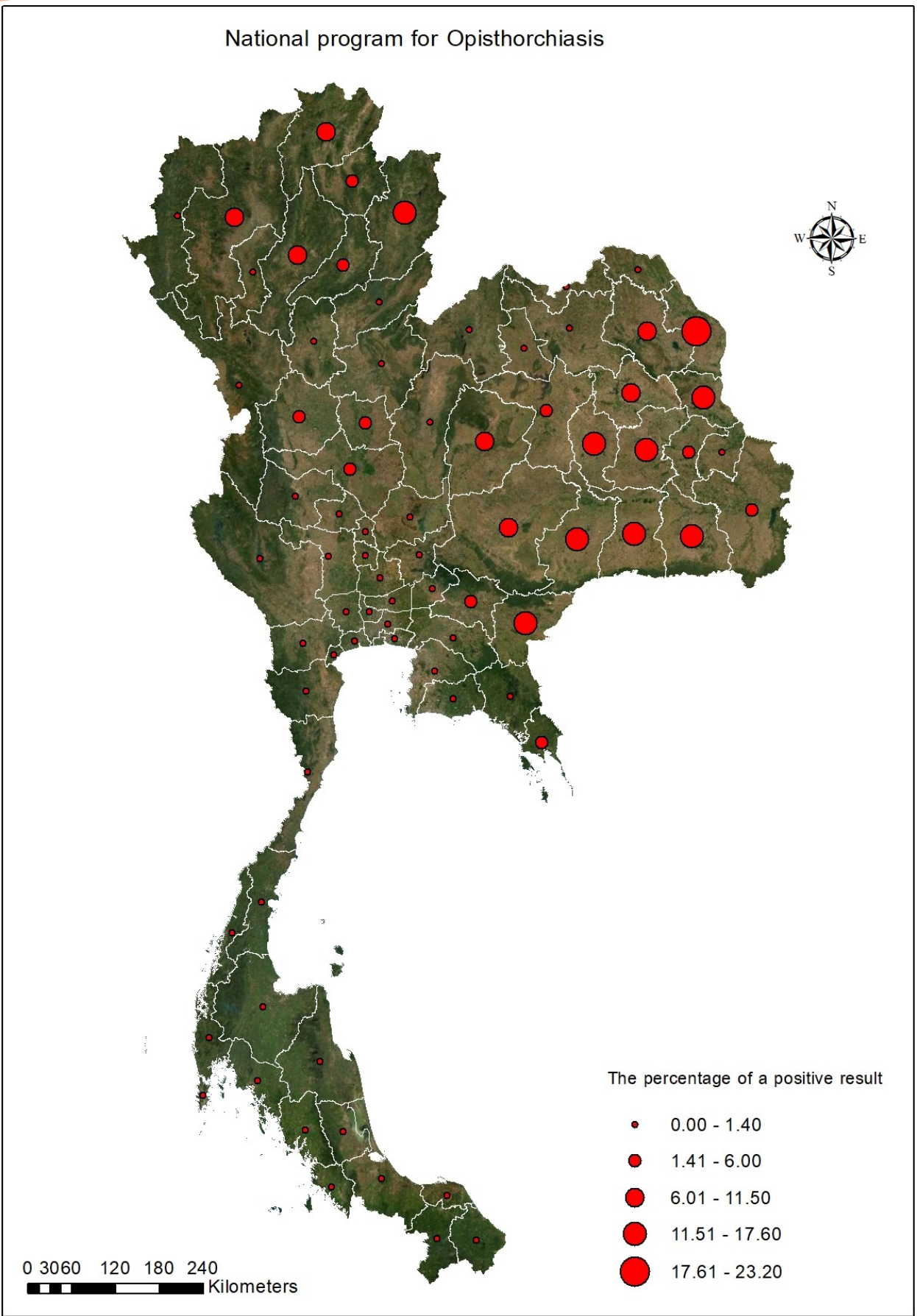

Figure 1: Show the National prevalence of Opisthorchiasis in each province of Thailand

Table 1: Demographic information of Opisthorchis viverrini infection showing among male and female groups

\begin{tabular}{|c|l|c|c|}
\hline \multirow{2}{*}{ Variable } & & \multicolumn{2}{|c|}{ Result } \\
\cline { 2 - 4 } & & Negative & Positive \\
\cline { 2 - 4 } & & Number [\%] & Number [\%] \\
\hline Sex & Male & $3,715[92.7]$ & $293[7.3]$ \\
\hline & Female & $5,685[96.4]$ & $211[3.6]$ \\
\hline
\end{tabular}




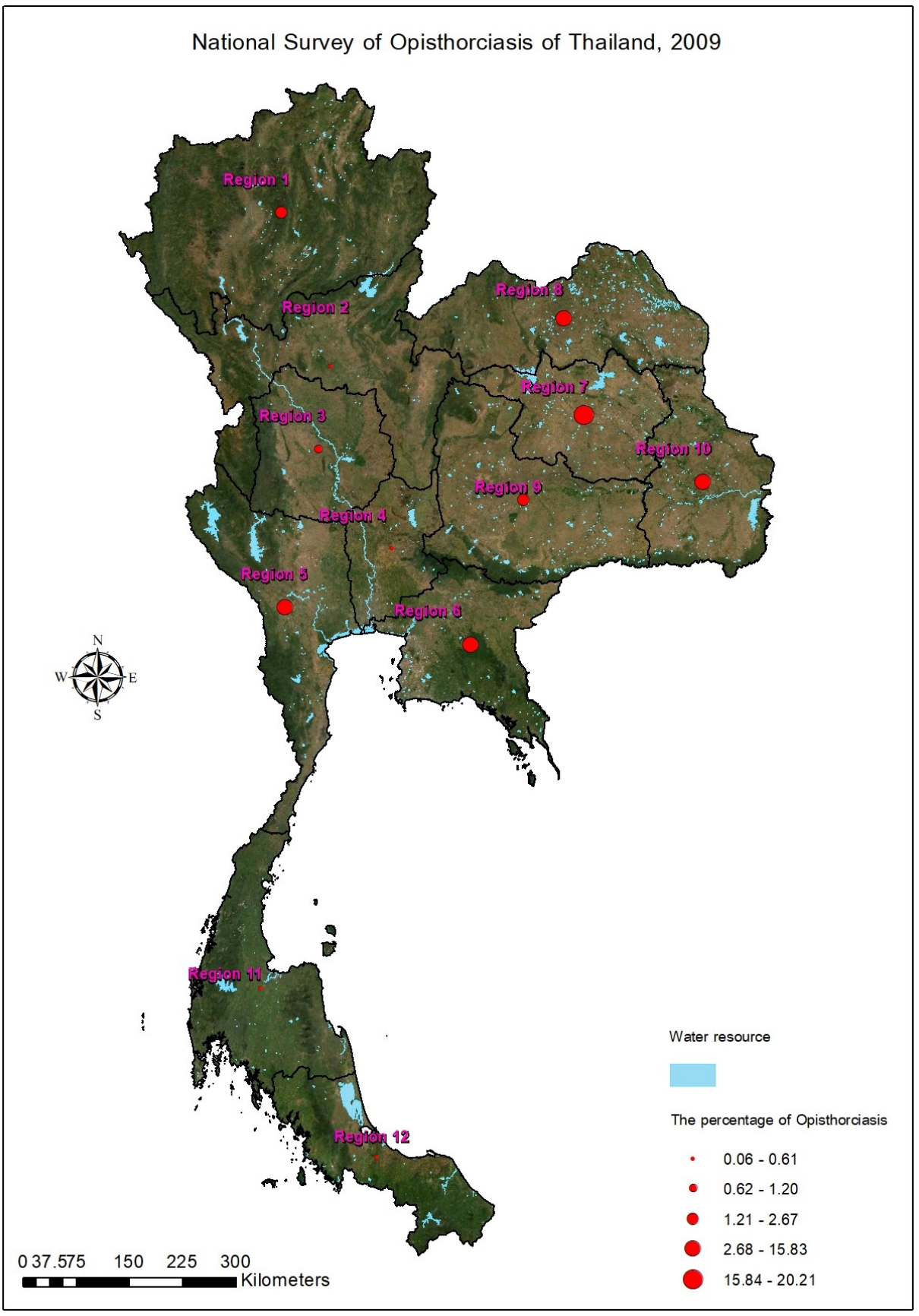

Figure 2: Showed the prevalence of Opisthorchiasis in 12 Public health regions of Thailand with water

The endemic area showed the big water reservoirs; Ubolratana dam which is the source transmission, and source of freshwater fishes act as a second intermediate host. After the operation the program and the strategy 2009, the prevalence slightly declines in Health region 5, 9 and 8 were $12.8 \%$ to $11.89 \%, 2.67 \%$ to $0.33 \%$ and $12.7 \%$ to $3.46 \%$ respectively. The overall opisthorchiasis was 3.98\%. (Figure 3). The major crucial outcome already showed the effectiveness of 10 years' strategic plan for the elimination of the liver fluke and CCA after running the prevalence declined from 2009 to 2014 were $8.13 \%$ to $4.00 \% \%$. The Bureau of General Communicable Diseases, Department of Disease Control, Ministry of Public Health established the national campaign for prevention and control for neglected tropical diseases especially Opisthorchiasis with the huge effective outcome and dramatically phenomenal of improving quality of life. 


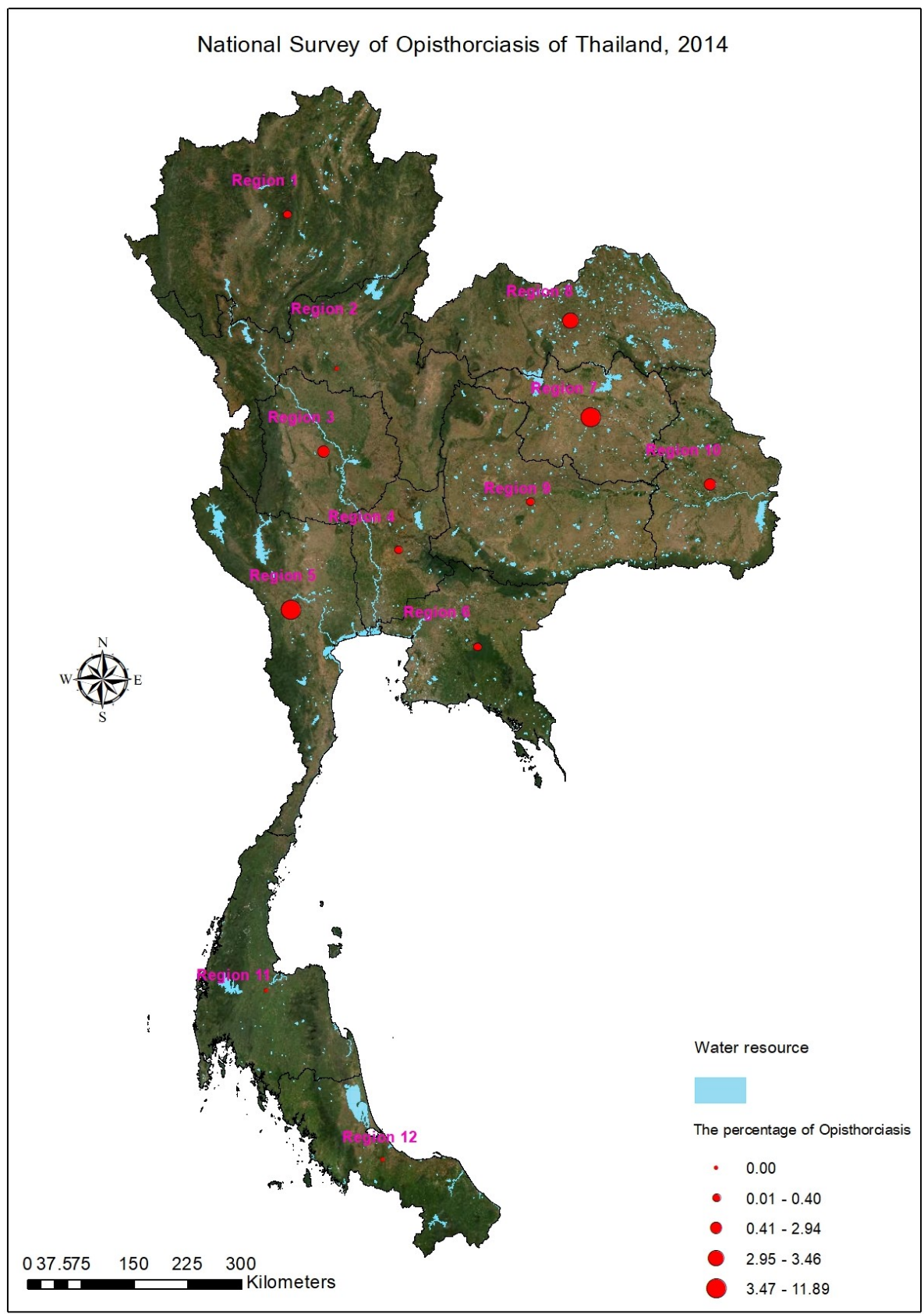

Figure 3: Showed the prevalence of Opisthorchiasis in 12 Public health regions of Thailand with water sources in year 2014

Table 2: The percentage and number of Opisthorchis viverrini infected in age and sex groups

\begin{tabular}{|l|l|l|l|c|c|c|}
\hline \multirow{2}{*}{ Variable } & \multirow{2}{*}{ Group[year] } & \multirow{2}{*}{ Sex } & \multicolumn{5}{|c|}{ Sample } \\
\cline { 4 - 7 } & & & \multicolumn{2}{|c|}{ Negative } & \multicolumn{2}{c|}{ Positive } \\
\cline { 3 - 7 } & & No. & \% & No. & \% \\
\hline & $<5$ & male & 175 & 100.0 & 0 & 0 \\
\hline & & female & 148 & 98.7 & 2 & 1.3 \\
\hline & $6-9$ & male & 237 & 97.9 & 5 & 2.1 \\
\hline & & female & 190 & 99.0 & 2 & 1.0 \\
\hline & $10-15$ & male & 206 & 98.6 & 3 & 1.4 \\
\hline & & female & 206 & 97.6 & 5 & 2.4 \\
\hline & $16-20$ & male & 122 & 97.6 & 3 & 2.4 \\
\hline
\end{tabular}




\begin{tabular}{|l|l|l|c|c|c|c|}
\hline \multirow{2}{*}{ Variable } & \multirow{3}{*}{ Group[year] } & \multirow{2}{*}{ Sex } & \multicolumn{5}{|c|}{ Sample } \\
\cline { 3 - 7 } & & & \multicolumn{2}{|c|}{ Negative } & \multicolumn{2}{c|}{ Positive } \\
\cline { 3 - 7 } & & No. & \% & No. & \% \\
\hline Age & & female & 126 & 98.4 & 2 & 1.6 \\
\hline & $21-25$ & male & 62 & 96.9 & 2 & 3.1 \\
\hline & & female & 121 & 97.6 & 3 & 2.4 \\
\hline & $26-30$ & male & 84 & 96.9 & 3 & 3.4 \\
\hline & & female & 166 & 97.1 & 3 & 2.4 \\
\hline & $31-35$ & male & 138 & 94.5 & 8 & 5.5 \\
\hline & & female & 292 & 98.3 & 5 & 1.7 \\
\hline & $36-40$ & male & 222 & 92.1 & 19 & 7.9 \\
\hline & & female & 511 & 96.2 & 20 & 3.8 \\
\hline & $41-45$ & male & 365 & 91.5 & 34 & 8.5 \\
\hline & & female & 713 & 96.7 & 24 & 3.3 \\
\hline & $46-50$ & male & 511 & 92.4 & 42 & 7.6 \\
\hline & & female & 824 & 96.5 & 30 & 3.5 \\
\hline & $51-55$ & male & 482 & 91.6 & 44 & 8.4 \\
\hline & & female & 761 & 95.8 & 33 & 4.2 \\
\hline & $56-60$ & male & 424 & 88.9 & 53 & 11.1 \\
\hline & & female & 623 & 95.4 & 30 & 4.6 \\
\hline & $61-65$ & male & 313 & 88.9 & 39 & 11.1 \\
\hline & & Female & 454 & 94.4 & 27 & 5.6 \\
\hline & $>66$ & male & 373 & 90.8 & 38 & 9.2 \\
\hline & & female & 548 & 96.0 & 23 & 4.0 \\
\hline
\end{tabular}

\section{Summary and Discussion}

The main outcome from the authors already showed evidence data of Opisthorchiasis approximately 4.0 $\%$ with the majority of the incidence showed in the group of age more than 56 years in the National program. Another finding the successful for prevention and control program under strategy from Ministry of public health. The data will support the policymaker in another country for prevention and control management including relevant with strategy support. It is seen as the classical demonstration of the demographical information of opisthorchiasis in Thailand during national surveillance programs.

The trends of the overall prevalence of opisthorchiasis decline were showed the crucial support from strategy and policy maker from 10 years' strategic plan for the elimination of the liver fluke and CCA. The Bureau of General Communicable Diseases, Department of Disease Control, Ministry of Public Health established the national campaign for prevention and control for neglected tropical diseases especially Opisthorchiasis with the huge effective outcome and dramatically phenomenal of improving quality of life. Liver flukes $(O$. viverrini.) are primarily a problem in the northeast, associated with the consumption of raw freshwater fish, and also associated with organic soil types. (Wattanayingcharoenchai et al., 2011) The first community-based study assessing in Russia. The epidemiology of $O$. felnius infection was showed $60.2 \%$ associated with woman, older, consumption of river fish, smoked, frozen and raw fish in the high-risk factors. The prevalence still high and require the prevention and control program as a recommendation. (Fedorova et al., 2020). The prevalence of Opisthorchiasis among inhabitant in Cambodia (2006-2011) already revealed with minute intestinal fluke showed $5.7 \%$ (1838 from $32,201)$, the most prevalence showed in central and southern regions showed $14.7 \%$ (1,575 from $10,721)$ the outcome showed national program still require are prevention and control. However, the prevalence of Soil-transmitted helminthiasis very high prevalence in Cambodia, the national program necessary require more effective intervention program (Yong et al., 2014.) In Thailand, the previous report of helminthiasis showed the prevalence rate of $15.7 \%$, in Northeast Thailand observed in 2001 (Jongsuksuntigul and Imsomboon, 2003). The previous of the national survey of helminthiasis was $18.1 \%$ in 2009 (Wongsaroj et al., 2014). The several factors associated with the prevalence such as variability between different geographic regions and also seasonal variations support the explanation for this discrepancy (Sithathaworn et al., 1997). The traditional local food in the northeastern regions of Thailand, the main food preparation includes the consumption of raw freshwater fish. This habit behaviour of the local people may also be related to poverty and the ease of consumption of local freshwater fish foods. The government and ministry of public health established the prevention and control program which increased education about the risks-of eating 
$\mathrm{W}$ fish is essential for the control of liver fluke infections. The Incidence of Opisthorchiasis, Clonorchiasis and intrahepatic cancer has been knowing more than 5 decades, however, the Department of Disease Control, Ministry of Public Health in Thailand encourage the campaign on the prevention and control of Opisthorchiasis, however the incidence still high level as several reported (Sripa et al., 2007 and Wongsaroj et al., 2014).

The prevalence slightly declines at the national level and still high in the endemic area Northeast which associates with the area of the high incidence of Cholangiocarcinoma (Jongsuksuntigul and Imsomboon 1997 and 2003, Sripa and Pairojkul, 2008 and Wongsaroj et al., 2014). This phenomenal showed facing to necessary and crucial need to establish a national program still require the National prevention and control program. The Department of Disease control collaborates with network establish the strategy under umbellar of Ministry of public health negotiated with the Thai government to launch a 10 years' strategic plan for the elimination of the liver fluke and CCA running from 2016-2026 "10 years' strategic plan for the elimination of the liver fluke and CCA running from 2016-2026". In addition to the Ministry of Public Health, this policy involves several other ministries including the Ministry of Education, the Ministry of Agriculture, the Ministry of the Interior, the Ministry of Communication and the Ministry of Foreign Affairs. After the operation of the strategy, the prevalence of Opisthorchiasis declines from $8.13 \%$ in 2009 to $3.98 \%$ in 2014 respectively. The strategies for controlling Neglected Tropical Diseases are still required as 1 . The minimization of human host reservoir and infection intensity using stool examination coverage $100 \%$ and treatment $100 \% 2$. The prevention of opisthorchiasis through sustainable hygienic health behaviours among risk population in the community; Health Education and Health Behavior Development through health literacy and School health program. 3. The interruption of helminths transmission through hygienic defecation in sanitary latrine among parasite infested population especially in hill tribe areas and remote areas. 4. Environmental Health Improvement. 5.Community participation and cooperation of agency involved. They require continued surveillance and control in certain highrisk areas and high-risk groups. These recommendations showed a persistently high prevalence of liver fluke infections which are associated with health behaviours, Environment factors and geographic Information system. Though, the recommendation, Ministry of Public health demonstrated that there are still requires the
National program and continue the program for prevention, control and eliminate for opisthorchiasis. We were able to show that strategy of controlling program still required for World Health organization to encourage another country for establishing the national program for control and eliminate Opisthorchiasis and another Tropical disease especially in Southeast Asian. Further national program and geographic information system and, environmental assessment, reservoirs and sociological studies are recommended to elucidate risk factors in the transmission of opisthorchiasis and another tropical disease in another country.

\section{Acknowledgements}

The authors greatly appreciate the financial support and encouragement received from, The following: Ministry of Public Health, the Bureau of General Communicable Diseases, Department of Disease Control, Ministry of Public Health, Mahidol University, Mahasarakham University, the Provincial Public Health Sectors, and Dr. Wara Meesomboon from the Bureau of General Communicable Diseases, Thailand. This project approved by the human ethic committee of Department of Diseases Control, Ministry of Public Health ICH-GCP Ref. No. 1/57-662 Approved 26 February 2014-25 February 2015

\section{Reference}

Bouvard, V., Baan, R., Straif K, Grosse, Y. Secretan, B. Ghissasi, F. E. Tallaa, L. B. Guha, N, Freeman, C. Galichet, L. Cogliano, V. and WHO International Agency for Research on Cancer Monograph Working Group., 2009, A Review of Human Carcinogens-Part B: Biological Agents. Lancet Oncol, Vol. 10(4), 321-322.

Buisson, Y., 2017, Control of Opisthorchis viverrini Infection for Cholangiocarcinoma Prevention. Bull Soc. Pathol Exot. Vol. 110(1), 61-67.

Dietrich, H. and Wegner, G., 1984, The Profile of the Trematodicidal Compound Praziquantel. Arzneimittelforschung, Vol., 34, 1132-1136.

Fedorova, O. S., Fedotova, M. M., Zvonareva, O. I., Mazeina, S. V., Kovshirina, Y. V., Sokolova, T. S., Golovach, E. A., Kovshirina, A. E., Konovalova, U. V., Kolomeets, I. L., Gutor, S. S., Petrov, V. A., Hattendorf, J., Ogorodova, L. M. and Odermatt, P., 2020, Opisthorchis felineus Infection, Risks and Morbidity in Rural Western Siberia, Russian Federation. PLoS Negl Trop Dis., Vol. 14(6). Doi: 10.1371/journal.pntd.0008421. 
ong, Y. I., Shin, H. E., Lee, S. E., Cheun, H. I., Ju, J. W., Kim, J. Y., Park, M. Y. and Cho, S. H., 2016, Prevalence of Clonorchis Sinensis Infection among Residents along 5 Major Rivers in the Republic of Korea. Korean $J$ Parasitol. Vol. 54(2), 215-219. doi: 10.3347/kjp.2016.54.2.215.

Jongsuksuntigul, P. and Imsomboon, T., 1997. The Impact of a Decade Long Opisthorchiasis Control Program i in Northeastern Thailand. Southeast Asian J Trop Med Public Health, Vol. 28(3), 551-557.

Jongsuksuntigul, P. and Imsomboon, T., 2003, Opisthorchiasis Control in Thailand. Acta Trop., Vol. 88, 229-232.

Katz, M., Chaves, A. and Pellegrino, J., 1972, A Simple Device for Quantitative Stool Thick Smear Technique in Schistosomiasis Mansoni. Rev. Inst. Med. Trop. Sao Pauls, Vol. 14, $397-$ 400.

Lun, Z. R., Gasser, R. B., Lai, D. H., Li, A. X., Zhu, X. Q., Yu, X. B., Fang, Y. Y., 2005, Clonorchiasis: A Key Foodborne Zoonosis in China. Lancet Infect Dis., Vol. 5(1):31-41.

Nithikathkul, C., Trevanich, A., Wongsaroj, T., Wongsawad, C. and Reungsang, P., 2017, Health Informatics Model for Helminthiasis in Thailand. Journal of Helminthology, Vol. 91(5), 528-533.

Qian, M. B., Utzinger, J., Keiser, J. and Zhou, X. N., 2016, Clonorchiasis. Lancet, Vol. 387(10020), 800-810.

Radomyos, B., Wongsaroj, T., Wilairatana, P., Radomyos, R., Praevanich, R. Meesomboon, V. and Jongsuksantikul, P. 1998, Opisthorchiasis and Intestinal Fluke Infection in Northern Thailand. Southeast Asian J Trop Med Public Health, Vol. 29,123-127.

Rim, H. J., 2005, Clonorchiasis: An Update. J. Helminthol, Vol. 79(3), 269-281.

Ritchie, L. S., 1948, An Ether Sedimentation Technique for Routine Stool Examinations. Bull U.S. Army Med Dept., Vol. 8, 326.

Sithithaworn, P., Pipitgool, V., Srisawangwong, T., Elkins, D. B. and Haswell-Elkins, M. R., 1997, Seasonal Variation of Opisthorchis Viverrini Infection in Cyprinoid Fish in Northeast Thailand: Implications for Parasite Control and Food Safety. Bull World Health Organ., Vol.75(2),125-131.

Sithithaworn, P. and Haswell-Elkins, M., 2003, Epidemiology of Opisthorchis viverrini. Acta Trop. Vol. 88, 187-94.

Sripa, B., Kaewkes, S., Sithithaworn, P., Mairiang, E., Laha, T., Smout, M., Pairojkul, C.,
Bhudhisawasdi, V., Tesana, S., Thinkamrop, B., Bethony, J. M., Loukas, A., Brindley, P. J., 2007, Liver Fluke Induces Cholangiocarcinoma. PLoS Med. Vol. 4(7), e201.

Sripa, B. and Pairojkul, C., 2008, Cholangiocarcinoma lesion from Thailand. Curr Opin Gatroenterol. Vol. 24(3), 349-356

Sripa, B., Bethony, J. M., Sithithaworn, P., Kaewkes, S., Mairiang, E., Loukas, A., Mulvenna, J., Laha, T., Hotez, P. J. and Brindley, P. J., 2011, Opisthorchiasis and Opisthorchis-Associated Cholangiocarcinoma in Thailand and Laos. Acta Trop., Vol. 120(Suppl 1): S158-S168.

Sripa, B. and Echaubard, P., 2017, Prospects and Challenges Towards Sustainable Liver Fluke Control, Trends Parasitol. Vol. 33(10), 799-812.

Suwannahitatorn, P., Webster, J., Riley, S., Mungthin, M. and Donnelly, C. A., 2019, Uncooked Fish Consumption among those at Risk of Opisthorchis viverrini Infection in Central Thailand, PLoS One, Vol. 14(1), e0211540.

Wattanayingcharoenchai, S., Nithikathkul, C., Wongsaroj, T., Royal, L. and Reungsang, P., 2011, Geographic Information System of Opisthorchis viverrini in Northeast Thailand. Asian Biomedicine, Vol. 5(5), 687-691.

Wongsaroj, T., Nithikathkul, C., Reungsang, P., Royal, L., Nakai, W., Krailas, D. and Ramasoota, P., 2012, Geographic Information of Helminthiasis in Thailand. International Journal of Geoinformatics, Vol. 8(3), 59-64.

Wongsaroj, T., Nithikathkul, C., Rojkitikul, W., Nakai, W., Royal L. and Rammasut, P., 2014, National Survey of Helminthiasis in Thailand. Asian Biomedicine, Vol. 8(6), 779-783.

World Health Organization, 1980, Manual of Basic Techniques for a Health Laboratory. World Health Organization Geneva, 384.

World Health Organization, 1990, Model Prescribing Information. Drugs used in Parasitic Diseases. Geneva: WHO, 86-87.

Yong, T. S., Chai, J. Y., Sohn, W. M., Eom, K. S., Jeoung, H. G., Hoang, E. H., Yoon, C. H., Jung, B. K., Lee, S. H., Sinuon, M. and Socheat, D., 2014, Prevalence of Intestinal Helminths among Inhabitants of Cambodia (2006-2011). Korean J Parasitol, Vol. 52(6), 661- 666.

Yoshida, I. Horie, S. and Akkavong, K., 2019, Predictors of Hookworm and Opisthirchis viverrini Infection among Aldolescents in Urban Laos: A Cross-Sectioanl Study. Res. Rep. Trop. Med., Vol. 10, 31-41. 